\title{
An Uncommon Variant of Wilms Tumor: Botryoid Intrapelvic Renal Mass
}

\author{
Onur Telli ${ }^{1}$ (D), Nuran Küçük² (D), Burcu Hanc1³ (D), Şükran Sarıkaya ${ }^{4}$ (D), Oktay Akça ${ }^{3}$ (D)

\begin{abstract}
${ }^{1}$ Department of Pediatric Urology, Lütfi Kırdar Kartal Training and Research Hospital, İstanbul, Turkey ${ }^{3}$ Department of Urology, Lütfi Kırdar Kartal Training and Research Hospital, İstanbul, Turkey
\end{abstract} \\ ${ }^{2}$ Department of Pediatric Nephrology, Lütfi Kırdar Kartal Training and Research Hospital, İstanbul, Turkey \\ ${ }^{4}$ Department of Pathology, Lütfi Kırdar Kartal Training and Research Hospital, İstanbul, Turkey
}

Infrequently, Wilms tumor (WT) can be detected as a polypoid structure in renal pelvis without any parenchymal component and may extend to the bladder. This uncommon type of WT is named as botryoid WT (BWT) (1). We report a rare case of a 5 -year-old girl, who was admitted to our clinic with a chief complaint of gross hematuria and weight loss. Urinary system ultrasonography revealed grade 2 hydronephrosis in the right kidney, and echogenicity (like renal stones or infected material) was observed in the renal pelvis and proximal ureter. Non-contrast computed tomography showed right enlarged inhomogeneous renal mass extending to collecting system with dilated renal pelvis and ureter (Figure 1). Punch biopsy and pelvic cytology demonstrated malignant neoplasia after ureterorenoscopy. Right laparoscopic nephroureterectomy was performed, and patholo- gy reported macroscopically a $6 \times 4 \times 2 \mathrm{~cm}$ grayish polypoid mass growing into renal pelvis extending into the proximal ureter (Figure 2). The tumor was containing blastemal, epithelial, and stromal components verifying WT as typical features. The tumor includes a triphasic pattern of blastema (40\%) and epithelial $(30 \%)$ and stromal tissues $(30 \%)$. The blastema was diffuse packed primitive small blue cells with scanty cytoplasm overlapping nuclei. The epithelial component was described as early tubular formation, glomeruli-like structures. The stromal component was a fibroblast-like stroma with myxoid background. The tumor cell was not identified as having anaplastic histology. The ureter was wide and its lumen was filled with coagulation necrosis. Immunohistochemically, the epithelial tumor cells were positive for WT-1 (Figure 3). The tumor was separated from
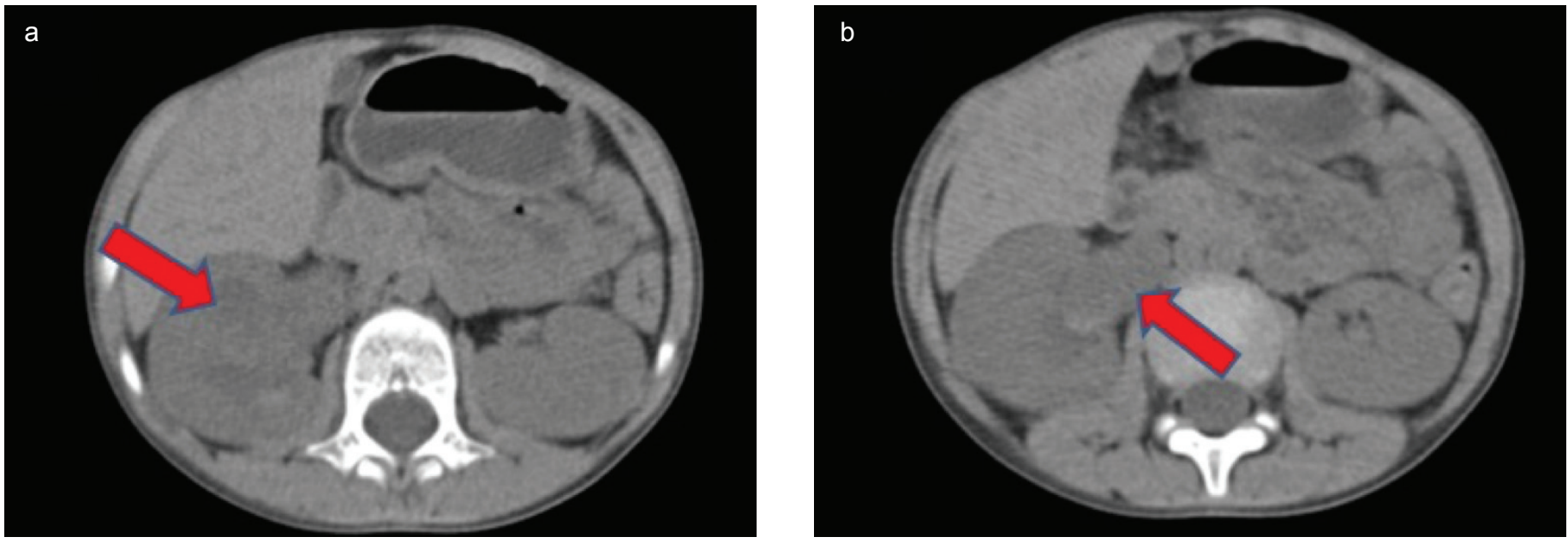

FIG. 1. a, b. Non-contrast computed tomography illustrated enlarged inhomogeneous right kidney consisting of multiple water-density masses, which filled the pelvicalyceal system (a). The masses extending into the right renal pelvis and proximal ureter (b).

Address for Correspondence: Onur Telli, Department of Pediatric Urology, Lütfi Kırdar Kartal Training and Research Hospital, İstanbul, Turkey e-mail: onurtelli@yahoo.com

Received: March 11, 2020

Accepted: June 24, 2020 •DOI: 10.4274/balkanmedj.galenos.2020.2020.3.59

Available at www.balkanmedicaljournal.org

ORCID iDs of the authors: O.T. 0000-0002-7454-7661; N.K. 0000-0002-2397-5826; B.H. 0000-0002-5232-6518; Ş.S. 0000-0002-9093-3933; O.A. 0000-0002-1259-6580.

Cite this article as:

Uslu S, Telli O, Küçük N, Hancı B, Sarıkaya Ş, Akça O. An Uncommon Variant of Wilms Tumor: Botryoid Intrapelvic Renal Mass Balkan Med J 2021;38:50-2

Copyright@Author(s) - Available online at http://balkanmedicaljournal.org/ 
other kidney tumors by its triphasic appearance. Stage II WT was diagnosed after clinical, imaging, and histologic findings. WT growing in a botryoid fashion is usually not infiltrating the pelvic wall, therefore intrapelvic botryoid growth should not be regarded as renal sinus/pelvic invasion and a reason for up staging a tumor (2). This kind of growth pattern may cause incorrect staging of the tumor. Therefore, it should be evaluated in detail by the clinicians to prevent incorrectly upgrading the stage of the tumor.

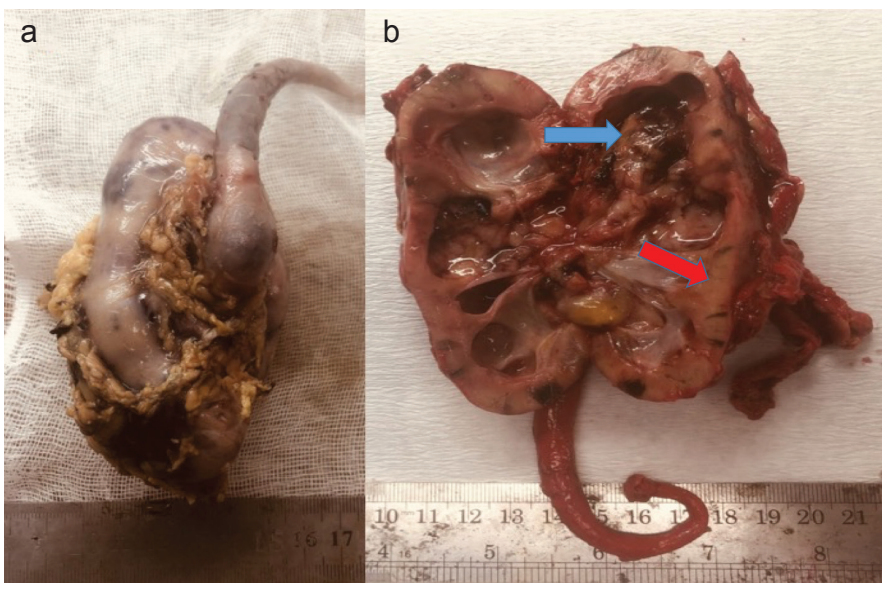

FIG. 2. a, b. Nephroureterectomy specimen. Grayish polypoid mass with coagulation necrosis (a). Botryoid sarcoma-like appearance occupied the right renal pelvicalyceal system, renal pelvis, and ureter (blue arrow indicates tumor and red arrow indicates normal kidney tissue) (b).

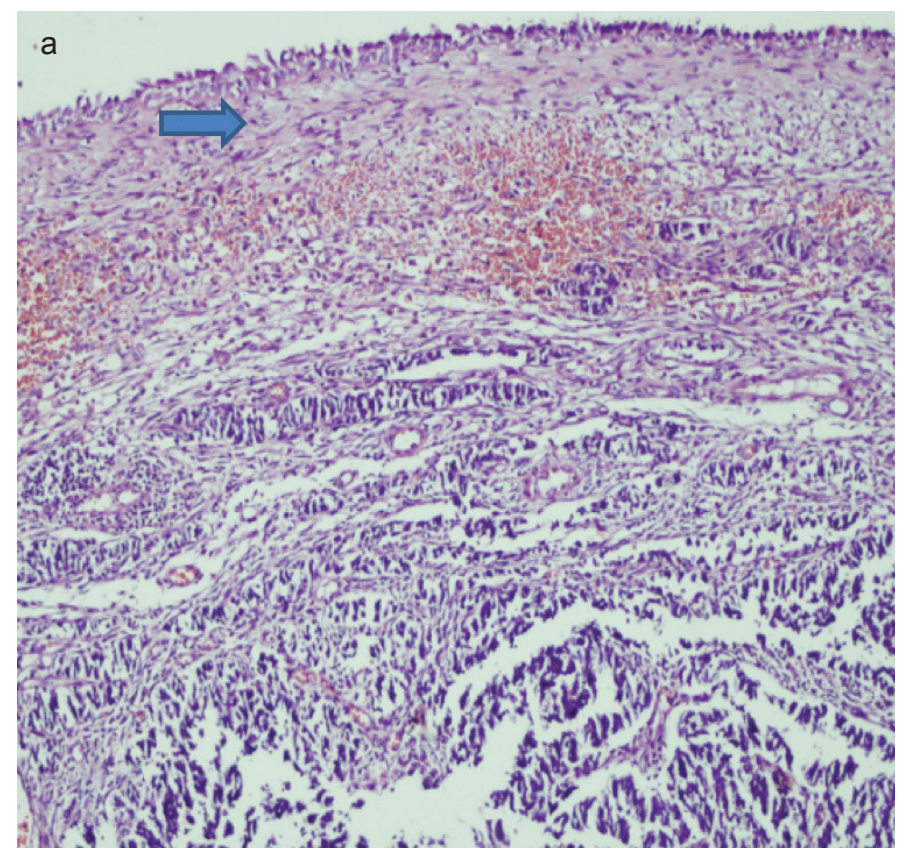

Moreover, WT in which tumor spreads intraperitoneally on biopsy should be staged as stage III. We performed an endoscopic biopsy (ureterorenoscopy) procedure that is not related with any tumor spread or any collecting system perforation that pathologists or oncologists may think as a peritoneal spread. There could be a concern; however, this is not like a biopsy that will cause perforation of tumor or any peritoneal implant. All procedures were performed in the lumen of the collecting system.

WT usually presents as an asymptomatic abdominal mass; however, the most common clinical finding in BWT is macroscopic hematuria. In addition to hematuria, dysuria, urinary tract infection, hydroureteronephrosis (secondary to obstruction), and loss of renal function (secondary to chronic obstruction) will be the clinical findings $(2,3)$. The diagnosis of BWT is quite difficult, because it is rarely described in the literature and is therefore ignored in the differential diagnosis. The malignant rhabdoid tumor of the kidney, rhabdomyosarcoma, hemangioma, or xanthogranulomatous pyelonephritis should be considered in the differential diagnosis $(4,5)$. In conclusion, clinicians should be aware of the existence of this unusual form of WT, which originates in the pelvis and extends into the ureter or bladder with macrohematuria.

Patient Consent for Publication: Written consent was obtained from the patient's parents. Author Contributions: Concept - N.K.; Supervision - O.A.; Data Collection and/or Processing - O.T., B.H., Ş.S.; Analysis and/or Interpretation - Ş.S.; Literature Search - N.K.; Writing Manuscript - O.T

Conflict of Interest: The authors have no conflicts of interest to declare.

Funding: The authors declared that this study has received no financial support.

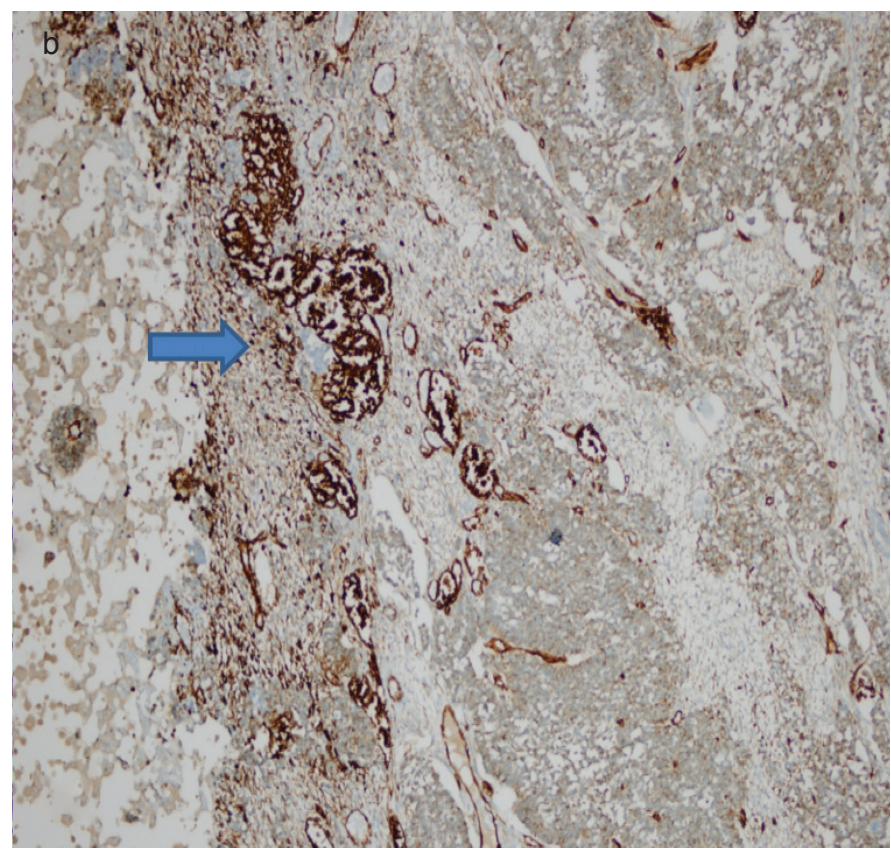

FIG. 3. a, b. Microscopic image of Botryoid Wilms tumor (surface cell is urothelial cell and tumor area [HEX100]) (a). Immunohistochemical staining for WT-1 (the epithelial tumor cells were positive) (b). 


\section{REFERENCES}

1. Yanai T, Okazaki T, Yamataka A, Kobayashi H, Lane GJ, Saito M, et al. Botryoid Wilms' tumor: A report of two cases. Pediatr Surg Int 2005;21:43-6. [Crossref]

2. Vujanić GM, Schiavo Lena M, Sebire NJ. Botryoid Wilms tumor: A non-existent"entity" causing diagnostic and staging difficulties. Virchows Arch 2019;474:227-34 [Crossref]
3. Nagahara A, Kawagoe M, Matsumoto F, Tohda A, Shimada K, Yasui M, et al. Botryoid Wilms' tumor of the renal pelvis extending into the bladder. Urology 2006;67:845. e15-7. [Crossref]

4. Mizuno K, Hayashi Y, Tozawa K, Iwatsuki S, Kojima Y, Kohri K. Single-nucleotide polymorphism in WT1 gene in a hyperplastic intralobar nephrogenic rest with botryoid protrusion. Urology 2010;76:149-52. [Crossref]

5. Tu B-W, Ye W-J, Li Y-H. Botryoid Wilms' tumor: Report of two cases. World J Pediatr 2011;7:274-6. [Crossref] 